and McCarthy 1984) and the cursor must be accurately placed at each joint. Specimen bones of known length can be measured to an accuracy of $0.2 \mathrm{~mm}$. The procedure takes an experienced person about five minutes, as against at least twice this time for orthoroentgenography.

\section{REFERENCES}

Green WT, Wyatt GM, Anderson M. Orthoroentgenography as a method of measuring the bones of the lower extremities. $J$ Bone Joint Surg 1946;28:60-5.

Helms CA, McCarthy S. CT scanograms for measuring leg length discrepancy. Radiology 1984;151:802.

Moseley CF. A straight-line graph for leg-length discrepancies. J Bone Joint Surg [Am] 1977;59-A:174-9.

\title{
CAISSON DISEASE OF THE TALUS: BRIEF REPORT
}

\author{
D. P. O'DOHERTY, I. G. LOWRIE, P. J. GREGG
}

Caisson disease of bone (dysbaric osteonecrosis) is a wellrecognised occupational hazard of diving that has become increasingly important in association with the search for oil in the North Sea.

We report a case involving the talus. This unfamiliar site has implications for the screening of individuals at risk, and medico-legally in compensation cases.

Case history. A 32-year-old white man gave a one-year history of intermittent, painful swelling of the ankles, worse on the right. Swelling had occurred about once a month, lasting four to five days, but between attacks the ankles were normal. No other joints were affected and he was otherwise fit and well, having had no previous major illness, taking no medication and denying alcohol abuse. He had worked in the North Sea as a commercial diver for about five years, undertaking non-saturation dives to 200 feet on helium-oxygen mixtures. He admitted to five attacks of Type 1 bends despite adhering to his firm's decompression tables.

There was no clinical abnormality in either ankle, and plain radiographs were equivocal and considered to be normal, but scintigraphy with ${ }^{99 \mathrm{~m}} \mathrm{Tc}$-diphosphonate showed a slight increase in activity in the whole of the right talus with a focal area posteriorly, near the os trigonum. Tomograms of the talus showed a wedgeshaped area of juxta-articular sclerosis (Fig. 1). Because of the symptoms, a subchondral fracture was suspected, and this was confirmed by arthrography (Fig. 2). Plain radiographs of the hips, knees and shoulders were all normal, as were a full blood count, the plasma viscosity and routine biochemistry.

Caisson disease of the talus was diagnosed and is being managed conservatively.

Discussion. We could find no previous reports of caisson disease of the talus. This suggests that current screening methods, based on the premise that most lesions are in

D. P. O'Doherty, FRCS Ed, Orthopaedic Registrar

The Royal Free Hospital, Pond Street, London NW3 2QG, England.

I. G. Lowrie, FRCS Ed, Senior Orthopaedic Registrar

P. J. Gregg, MD, FRCS, Professor of Orthopaedic Surgery

University Department of Orthopaedic Surgery, Glenfield General

Hospital, Groby Road, Leicester LE3 9QP, England.

Correspondence to Mr D. P. O'Doherty.

(C) 1987 British Editorial Society of Bone and Joint Surgery

$0301-620 \mathrm{X} / 87 / 5 \mathrm{R} 31 \$ 2.00$ the long bones (Gregg and Walder 1986), may underestimate the prevalence of bone damage. It is important that all possible sites for caisson disease are documented because of the increasing number of compensation claims for significant disability. Caisson disease tends to affect otherwise fit young men, so compensation claims may be very high and failure to

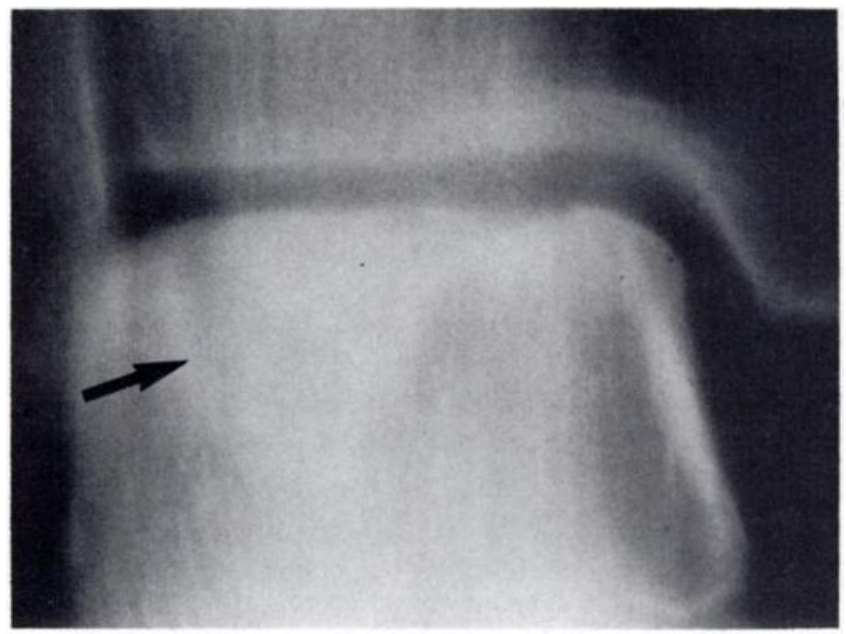

Fig. 1

Anteroposterior tomogram of the right talus, showing a wedge-shaped area of sclerosis.

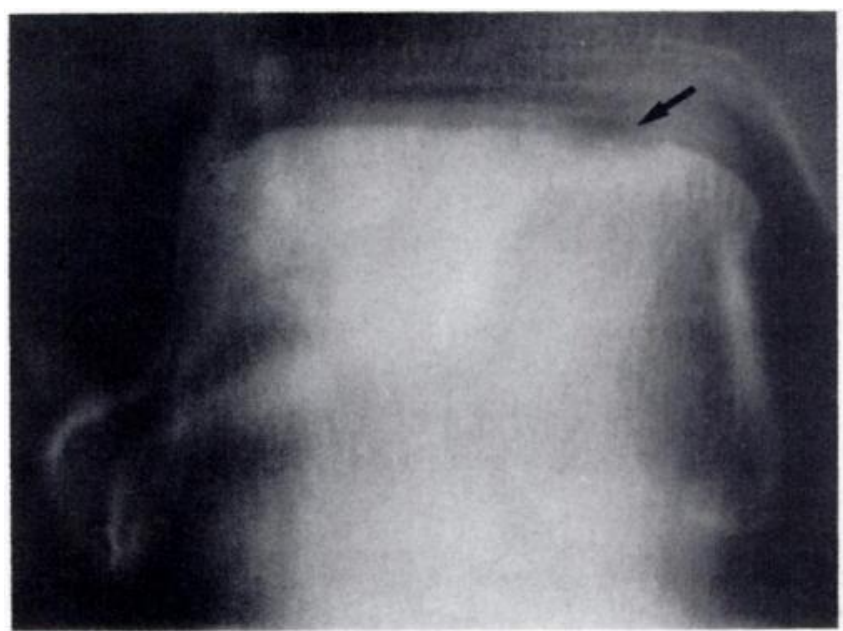

Fig. 2

Anteroposterior arthrogram of the right ankle showing a defect in the articular cartilage and subchondral bone. 
document all the sites affected may prejudice those with unusual lesions.

Although plain radiographs remain the chief diagnostic method, this case demonstrates the value of other techniques, in that a radioisotope bone scan detected a definite abnormality despite equivocal plain radiographs. Scintigraphy is a sensitive method for detecting early bone necrosis (Gregg and Walder 1980), and may have a role in the surveillance of divers (Macleod et al. 1982). The development of pain near a known bone lesion should lead to a search for evidence of structural failure of bone; tomography and arthrography may be helpful.

\section{REFERENCES}

Gregg PJ, Walder DW. Scintigraphy versus radiography in the early diagnosis of experimental bone necrosis: with special reference to caisson disease of bone. J Bone Joint Surg 1980;62-B:214-21.

Gregg PJ, Walder DN. Caisson disease of bone. Clin Orthop $1986 ; 210: 43-54$

Macleod MA, McEwan AJB, Pearson RR, Houston AS. Functional imaging in the early diagnosis of dysbaric osteonecrosis. $\mathrm{Br} J$ Radiol 1982:55:497-500.

\title{
BONE SCANNING FOR HIP FRACTURE IN PATIENTS WITH OSTEOARTHRITIS: BRIEF REPORT
}

\author{
E. N. COLHOUN, S. R. JOHNSON, J. A. FAIRCLOUGH
}

Orthopaedic surgeons are frequently faced with the difficult problem of an elderly patient who presents with hip pain and inability to bear weight, but whose radiograph shows no fracture. We have demonstrated elsewhere that radio-isotope bone scanning can reveal the presence of a fracture at an early stage (Fairclough et al. 1987), but from that study we excluded patients with ipsilateral osteoarthritis. This was because we thought that the increased uptake due to the osteoarthritis would mask that of the fracture. We have therefore studied, in two different ways, the relationship between osteoarthritis and fractures.

Incidence of osteoarthritis in fractured hips. First, we reviewed retrospectively the radiographs of 200 patients with subcapital fractures and found that only $2 \%$ had ipsilateral osteoarthritis, while a control series of 200 without fracture, matched for age and sex, had a $24 \%$ incidence. By contrast, of 200 patients with intertrochanteric fractures $26 \%$ had osteoarthritis; a very similar incidence to the $29 \%$ we found in 200 similarly matched controls.

Scanning for fracture in osteoarthritic hips. Secondly, we conducted a prospective study of early bone scanning in 26 patients, each with a painful hip, inability to bear weight, no radiographic evidence of a hip fracture, but with osteoarthritis in the painful hip. There were 15 men and 11 women; their ages ranged from 60 to 81 years (mean 71.7). Fourteen of the 26 patients had mild osteoarthritis, in seven it was moderate and in five severe.

In all these 26 cases the isotope uptake was

E. N. Colhoun, FRCR, Senior Registrar in Radiology

University Hospital of Wales, Heath Park, Cardiff CF4 4XW, Wales.

S. R. Johnson, FRCS Ed, Registrar

J. A. Fairclough, FRCS, Senior Lecturer

Department of Traumatic and Orthopaedic Surgery, Cardiff Royal Infirmary, Cardiff CF2 1SZ, Wales.

Correspondence to Dr E. N. Colhoun.

(C) 1987 British Editorial Society of Bone and Joint Surgery $0301-620 X / 87 / 5 R 29 \$ 2.00$ increased in the hip region. This increase extended to the femoral neck where the osteoarthritis was moderate or severe, but was largely confined to the region of the acetabulum and the femoral head in those with early disease. In three of the 26 patients $(12 \%)$, the bone scan also revealed an intertrochanteric fracture which subsequently became obvious on radiographs. There was one fracture in association with each of the three grades of severity of the osteoarthritis.

Discussion. Osteoarthritis causes increased isotope uptake in the acetabulum, the femoral head and the femoral neck; its intensity reflects the severity of the disease. Our concern that occult fractures would be masked by this increase was reduced considerably when our retrospective study confirmed the widely held view that, in association with osteoarthritic hips, intertrochanteric fractures are much more common than subcapital fractures. None of the 26 patients in our prospective study had a subcapital fracture, but on rare occasions these are associated with early osteoarthritis. Fortunately, in such early cases, the small amount of isotope uptake resulting from the early degeneration is unlikely to mask the band of increased activity which indicates an occult subcapital fracture.

In the much more common intertrochanteric fracture, scanning readily establishes the diagnosis even in the presence of osteoarthritis. In all three of our patients with this combination, the band of increased activity marking the fracture was clearly separated from the increased activity in the hip joint region.

We conclude that even in the presence of ipsilateral osteoarthritis, radio-isotope bone scanning provides an accurate means of detecting or excluding an occult proximal femoral fracture.

\section{REFERENCE}

Fairclough JA, Colhoun EN, Johnston D, Williams LA. The elderly painful hip: prediction of the patients at risk of developing a fracture of the femoral neck using isotope bone scanning. $J$ Bone Joint Surg [Br] 1987;69-B:251-3. 